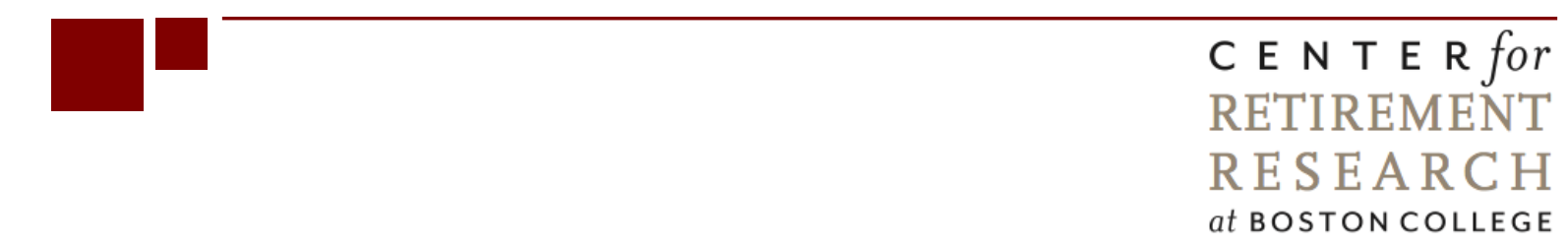

\title{
UNDERSTANDING THE GROWTH IN FEDERAL DISABILITY PROGRAMS: WHO ARE THE MARGINAL BENEFICIARIES, AND HOW MUCH DO THEY COST?
}

\author{
Adele Kirk \\ CRR WP 2012-1 \\ Date Released: January 2012 \\ Date Submitted: November 2011 \\ Center for Retirement Research at Boston College \\ Hovey House \\ 140 Commonwealth Avenue \\ Chestnut Hill, MA 02467 \\ Tel: 617-552-1762 Fax: 617-552-0191 \\ http://crr.bc.edu
}

Adele Kirk is an assistant professor of public policy at the University of Maryland, Baltimore County. The research reported here was performed pursuant to a grant from the U.S. Social Security Administration (SSA) funded as part of the Retirement Research Consortium (RRC). The opinions and conclusion expressed are solely those of the author and do not represent the opinions or policy of SSA, any agency of the federal government, the RRC, the University of Maryland, Baltimore County, or Boston College.

(C) 2012, Adele Kirk. All rights reserved. Short sections of text, not to exceed two paragraphs, may be quoted without explicit permission provided that full credit, including $($ C notice, is given to the source. 


\title{
About the Steven H. Sandell Grant Program
}

This paper received funding from the Steven H. Sandell Grant Program for Junior Scholars in Retirement Research. Established in 1999, the Sandell program's purpose is to promote research on retirement issues by scholars in a wide variety of disciplines, including actuarial science, demography, economics, finance, gerontology, political science, psychology, public administration, public policy, sociology, social work, and statistics. The program is funded through a grant from the Social Security Administration (SSA). For more information on the Sandell program, please visit our website at: http://crr.bc.edu/opportunities/steven_h._sandell_grant_program_2.html, send e-mail to crr@bc.edu, or call Marina Tsiknis at (617) 552-1092.

\section{About the Center for Retirement Research}

The Center for Retirement Research at Boston College, part of a consortium that includes parallel centers at the University of Michigan and the National Bureau of Economic Research, was established in 1998 through a grant from the Social Security Administration. The Center's mission is to produce first-class research and forge a strong link between the academic community and decision makers in the public and private sectors around an issue of critical importance to the nation's future. To achieve this mission, the Center sponsors a wide variety of research projects, transmits new findings to a broad audience, trains new scholars, and broadens access to valuable data sources.

\author{
Center for Retirement Research at Boston College \\ Hovey House \\ 140 Commonwealth Avenue \\ Chestnut Hill, MA 02467 \\ phone: 617-552-1762 fax: 617-552-0191 \\ e-mail: crr@bc.edu \\ crr.bc.edu
}

Affiliated Institutions:

The Brookings Institution

Massachusetts Institute of Technology

Syracuse University

Urban Institute 


\begin{abstract}
Supplemental Security Income (SSI) and Social Security Disability Insurance (SSDI), the two work disability programs administered by the Social Security Administration (SSA), have been marked by concerns about target efficiency since their inception. This study uses SSA administrative data linked with National Health Interview Survey data (NHIS) to examine health status, labor force participation at time of NHIS interview, and linked mortality data to examine mortality during the period following NHIS interview. The self-reported health status data present two strong and consistent patterns: denied applicants report being in considerably worse health than non-applicants, and beneficiaries appear to be sicker yet. In logit models among disability beneficiaries, women are significantly less likely to report excellent/very good health, but race has no significant effect. While being female decreased the probability of good health, it has no significant effect on the probability of reporting no work limitation at time of interview among beneficiaries. Although race was not significant in the model of self-reported health, both Hispanics and non-Hispanic blacks are significantly more likely to report no work limitation at time of interview. This study has important limitations. NHIS respondents who link to the SSA administrative data may not be representative of all individuals with disability application histories. In addition, individuals must live long enough after disability determination to be drawn into an NHIS sample, and these results reflect the experience of that subsample of disability applicants who do not die during the determination process or soon thereafter.
\end{abstract}




\section{Introduction}

Supplemental Security Income (SSI) and Social Security Disability Insurance (SSDI), the two work disability programs administered by the Social Security Administration (SSA), have been marked by concerns about target efficiency since their inception. Despite these concerns, entry criteria have been gradually relaxed over the years, and enrollment has grown tremendously. Research has identified a number of factors contributing to the growth of these disability programs. Some growth is attributable to demographic shifts, such as the aging of the population and the increased labor force participation of women. But research has identified other factors whose common feature is to increase the economic incentives to apply for disability benefits, including local economic conditions, the increase in the normal retirement age, changes in benefit levels, and changes in other programs, such as state general assistance programs.

Three related lines of research have informed the policy discussion regarding the target efficiency of the Social Security Administration's disability programs. One line endeavors to directly estimate the number of disability beneficiaries who would be working in the absence of the program. A second line examines the dramatic increase in the number of working-age individuals reporting disability and the corresponding growth in the disability programs, and attempts to identify the health and non-health-related drivers of that growth. A third line tries to assess the accuracy of SSA's disability determination process: what percentage of beneficiaries should the SSA have rejected as non-disabled, and what percentage of rejected beneficiaries should have been accepted?

The first line of research involves efforts to estimate the target efficiency of the disability programs directly: what percentage of beneficiaries would be working in the absence of the program? Efforts to estimate the work-disincentive effects of the program econometrically have yielded a wide range of estimates, some very high. Parsons $(1980,1982)$ for example, finds that the work disincentive effects of SSDI can account for virtually all of the decline in male labor force participation rate in recent decades. In a seminal 1989 paper, John Bound proposed a different approach: he argued that individuals rejected for disability benefits may serve as a comparison group to successful disability applicants, and that on average, rejectees should be healthier than successful applicants. Thus he argued that the labor force participation of rejected applicants represents an upper bound on the estimate of the labor force participation of beneficiaries in the absence of the program. Using this approach, he found that about half of 
rejected applicants had worked in the past year, and one-third reported working in the past month (Bound, 1989). Bound's sample was limited to older men and focused only on SSDI. Subsequent work using Bound’s comparison-group approach have yielded widely varying estimates of labor force participation among rejected applicants. Bound, Burkhauser, and Nichols (2002) use the 1990-93 Survey of Income and Program Participation and find work rates among rejected SSDI applicants of 31 percent and among rejected SSI applicants of 19 percent. Chen and van de Klaauw use 1990-1996 SIPP data linked to SSA administrative data, and find work rates of only about 22 percent (2008). Using administrative data only, von Wachter, Song, and Manchester find much higher work rates of between 58-67 percent in the decade following rejection (2007). Similarly, Kirk and Wheatcroft find that half of rejected applicants are working at the time of NHIS interview using 1994-96 linked NHIS-SSA data (2008).

Several factors may account for the differences in estimates using this fairly straightforward comparison group approach. The evidence suggests that the SSDI and SSI populations are different from each other, and analyses ideally should incorporate information about participation in both programs while generating separate estimates for the three distinct populations: SSDI applicants (or rejected applicants), SSI, and dual applicants/rejectees. A second factor may be the time period in which rejected applicants are observed, and the administrative data used to analyze application outcomes. The two studies that find higher work rates - von Wachter, Song, and Manchester, and Kirk and Wheatcroft - follow rejected applicants for a longer period of time than the studies finding lower work rates, and logit models of work among rejectees using the NHIS-SSA linked data suggest that time since rejection is a significant predictor of work. Similarly, the administrative data used by von Wachter, Song, and Manchester, and the linked NHIS-SSA data used by Kirk and Wheatcroft incorporate higher level appeal decisions and information about actual disability payments, thus providing richer information about the ultimate disposition of disability applications than the 831 file alone used by Chen and van der Klauuw.

A second line of research seeks to explain the tremendous growth in the program over the years. Possible drivers of that growth include demographic changes, secular increases in disability, changes in the screening criteria used by SSA, and what might generally be termed economic incentives to apply for disability benefits. 
Autor and Duggan (2006) identify several critical changes in the disability programs over the years, and attribute the rise in enrollment in recent years to three major factors:

- The tightening of eligibility and increase in continuing disability reviews in the early 1980s led to a backlash and Congressional action that significantly altered the screening process. In particular they note that these changes made it easier to be accepted for disability for back pain and mental illness. Autor and Duggan point out that not only did these changes increase the number of disability beneficiaries, but greatly increased the length of time beneficiaries are on the disability rolls, because both conditions are low mortality and may occur at relatively young ages.

- A second important change is the rise over the years in the replacement rate - the ratio of disability benefits to wage earnings prior to disability. Because disability benefits were indexed to the inflation rate, and because the wages of low-wage workers in particular grew more slowly than inflation, this led to an increase in the replacement rate for lowwage workers, and thus increased the economic incentives to apply for disability benefits.

- The increase in female labor force participation has increased the number of workers insured for disability benefits, i.e., workers with sufficient work history to qualify for SSDI.

Gruber and Kubik (1994) find that increases in rejection rates decrease application for disability benefits. They also find some evidence that more work-capable individuals are more sensitive to changes in denial rates, suggesting that increases in denial rates target their incentive effects to more-able individuals.

Duggan, Rosenheck, and Singleton examine changes in enrollment in the VA's Disability Compensation (DC) program following a rule change regarding diabetes claims for Vietnam veterans (2006). They find that this narrow change in eligibility rules increased DC enrollment by 7.6 percentage points. They also find that the changes increased the sensitivity of the program to local economic conditions, suggesting an interactive effect between program stringency and adverse economic shocks. 
Autor and Duggan (2003) similarly argue that the disability rolls have become a significant alternative to unemployment in response to adverse labor shocks, especially among high school dropouts. They find that were it not for the increasing generosity and availability of disability benefits, the unemployment rate of high school dropouts would be about four percentage points higher. As with the VA study, they argue that there is a relationship between the stringency of screening and the responsiveness of DI enrollment to labor market conditions. They find that the looser criteria and increased sensitivity to labor market shocks has resulted in a disability beneficiary population that is younger, has lower mortality, and is poorly educated relative to earlier recipients.

However, von Wachter, Song, and Manchester come to slightly different conclusions using a large sample of longitudinal administrative data (2007). They find that the earnings histories of disability applicants suggests that a significant population of marginal workers apply for disability benefits because of adverse economic conditions, but that many if not most such applicants are being denied benefits. They also find that the decline over time in the economic circumstances in beneficiaries is due to an increase in those with low lifetime earnings, rather than those who experience an adverse economic shock.

The increase in the normal retirement age (NRA) has created another economic incentive to apply for disability benefits. The NRA increase reduces benefits taken prior to reaching the NRA and thus increases the relative attractiveness of SSDI benefits. Duggan, Singleton, and Song (2005) find that 0.6 percent of men and 0.9 percent of women on SSDI are receiving benefits due to the changes in the NRA. They argue that these effects will increase as those fully exposed to the increase in retirement age reach their 50s and 60s.

However, some research suggests that at least some portion of the increase in disability enrollment is due to secular increases in disabling conditions among the non-elderly population.

Lakdawalla and colleagues examine trends in self-reported disability over time using the National Health Interview Survey (2004). After adjusting for compositional changes in the population, they find higher rates of reported disability over time for non-elderly individuals, particularly for younger adults aged 30-49 years, whose rates of self-reported disability increased by more than 50 percent between 1984 and 2000. Increases in disability were limited to the nonelderly: self-reported disability declined over the same period for adults over age 65 . They explore alternate hypotheses regarding the possible drivers of the increase in non-elderly 
disability rates, including increases in obesity; technological change; and economic incentives to apply for disability benefits. They find evidence that change in obesity is a strong driver of increases in disability among individuals in their 50s, with some evidence of obesity as a factor in younger ages. However, the obesity hypothesis cannot explain why rates of disability are increasing for the non-elderly yet decreasing for the elderly given that the increase in obesity has occurred in all age groups. They then examine whether the changing economic incentives to apply for disability might explain the increase in self-reported disability among the non-elderly seen in their data. They argue that the economic incentives hypothesis would predict greater increases in self-reported disability among lower-wage workers, less-educated workers, and nonworkers because it is those groups commonly identified as most subject to increased economic incentives to apply for disability. They do not find evidence in the data for such differential increases - they find that self-reported personal-care and routine-needs disability have increased equally among workers and non-workers, and across educational groups.

Steven Kaye (2003) also argues that at least some of the rise in disability enrollment is due to increases in disabling conditions. He uses the NHIS and finds that for each potentially limiting condition, the proportion reporting an activity limitation or an inability to work have remained constant, but that the prevalence of these conditions has increased. He follows Lakdawalla et al. in speculating that these increases in prevalence may be due to increased rates of obesity, and also suggests that the 1991 recession increased rates of stress-related conditions.

A more limited literature tries to assess the accuracy of the disability screening process. Benitez Silva, Buchinsky, and Rust (2006) argue that disability applicants' self-reported disability status and the SSA's ultimate award decision are "noisy but unbiased" measures of true underlying disability status. (Given the considerable controversy about the reliability of selfreported work limitation and other self-reported health measures in models of labor force participation, they devote another paper to justifying the assertion that survey respondents do not exaggerate their limitations (Benitez-Silva, et al., 2000).) They estimate that approximately 20 percent of awards and 60 percent of rejections are made in error, and these results are generally robust to variations in assumptions. While Autor and Duggan argue that part of the dysfunctionality of the current determination process lies in the high percentage of initial rejections overturned at the Administrative Law Judge (ALJ) level, Benitez-Silva and colleagues disagree. They find evidence that rejected applicants self-select into the appeal process, i.e., 
those that appeal generally have stronger cases than those who don't, and that the ALJ level works to reduce rejection errors without adding substantially to award errors.

\section{Data}

This study uses seven years of pooled NHIS data (1998-2004), which have been linked to SSA administrative data as well as mortality information. We will refer to these files as the linked NHIS-SSA data. The NHIS is a cross-sectional household interview survey of the civilian non-institutionalized population of the United States. The NHIS collects data on a range of health topics as well as socio-demographic characteristics and employment status. Eligible NHIS respondents were linked to their corresponding SSA records. These records contain administrative data on disability and old-age program participation from the Master Beneficiary Record (MBR) file, which contains information on applications for and receipt of benefits under the Old Age, Survivors, and Disability Insurance (OASDI) program, and the Supplemental Security Record file, which contains information on SSI application and receipt. The linked data include enrollment information from the MBR file for the period 1962-2008, and information from the SSR file for the years 1974-2008. We use the linked SSA data to determine application history at time of interview, including current beneficiary status and date of most recent disability determination, if any. We also use the SSA 831 File to provide additional information about the application for disability benefits, particularly the diagnostic codes for the primary impairment.

The linked NHIS-SSA files also are linked to mortality follow-up data using the National Death Index (NDI). Mortality follow-up is ascertained from the time of NHIS interview through December 31, 2006. (We use the term respondent-assessed rather than self-reported to describe interview responses to the NHIS because survey respondents answer on behalf of other family members as well as themselves.) We use NDI data to determine mortality of linked NHIS respondents during follow-up.

\section{Sample}

Our full sample includes NHIS adults aged 25-62 years at interview, eligible for linkage and linked to SSA data $(n=163,395)$. NHIS respondents who refused to provide their Social Security 
number or other personal identifying information were not eligible for linkage to SSA data and not all eligible respondents were successfully linked. Similarly, our subsample of adults linked to mortality data yields a sample of 162,861 .

As part of our exploration of labor force participation, we focus on respondents who have been denied SSDI or SSI benefits prior to interview; that sub-sample includes 3,761-7,373 respondents depending on the set of covariates used.

Definition of Applicant Status. Defining a participant's applicant status with the Social Security Administration is difficult, due to the complex application history of many applicants and beneficiaries. A substantial number of current beneficiaries have at least one rejected application before acceptance, thus it is important to carefully define the point at which applicant status is determined. In addition, we examine both SSI and SSDI program participation, and many respondents have diverse histories in both programs, e.g., rejected from one program, but a beneficiary in the other. For the purposes of this analysis, we elected to create mutually exclusive categories of enrollment status.

Two general principles guided categorization of applicant status. The first is that applicant status is defined as of the date of the NHIS interview and reflects application history with the SSA up to the date of interview. The second is that a hierarchy of status is established whereby a person who is a beneficiary in one program and a rejectee in the other program is classified as a beneficiary, and not as a rejectee. The rationale for this is that the participant's successful beneficiary status is most likely to be the stronger force shaping life circumstances at interview. With those principles in mind, we used the SSA administrative data to classify respondents into seven mutually exclusive categories:

- $\quad$ Rejected from SSDI: respondents who have a history of having been rejected as a primary beneficiary from the SSDI program at some point prior to NHIS interview, and are not a current beneficiary in either SSDI or SSI at the time of interview.

- Rejected from SSI: respondents who have a history of having been rejected as a primary beneficiary from the SSI program at some point prior to NHIS interview, and are not a 
current beneficiary in either SSDI or SSI at the time of interview.

- Dual Rejectee: respondents who have a history of having been rejected as a primary beneficiary from both the SSDI and the SSI programs at some point prior to NHIS interview, and are not a current beneficiary in either SSDI or SSI at the time of interview.

- SSDI Beneficiary: respondents who are current primary SSDI beneficiaries at the time of NHIS interview, as indicated by the MBR data.

- SSI Beneficiary: respondents who are current primary SSI beneficiaries at the time of NHIS interview, as indicated by the SSR data.

- Dual Beneficiary: respondents who are current primary beneficiaries of both the SSDI and SSI programs at the time of NHIS interview, as indicated by the MBR and SSR data.

- Non-applicant: This category includes individuals who are not classified as either rejectees or current beneficiaries in either program at the time of NHIS interview. This category includes a small number of individuals who for some reason were beneficiaries in one or both programs prior to interview, but were not in current payment status at the time of interview, i.e., they were no longer beneficiaries at time of interview. However, this category is dominated by the vast majority of adult respondents who have no history of having applied for disability benefits under SSDI or SSI.

\section{Methods}

Our examination of health differences among denied applicants, beneficiaries, and those who never apply is primarily descriptive. We first compare respondent-assessed measures of health among the different applicant status groups and conduct chi-square tests for significant differences between groups. We examine mortality during follow-up by using the linked National Death Index (NDI) data to create a binary measure of death during the follow-up period and a time-to-event measure of the number of days between date of NHIS interview and date of death or censoring. We estimate a Cox proportional hazard model of mortality using applicant 
status, and participant age as covariates, and report the hazard ratio of mortality for rejectees, beneficiaries, and non-applicants.

In our analysis of labor force participation, we first compare the observed work rates and reported work limitation of denied applicants, beneficiaries, and non-applicants. We also examine work among rejectees and self-reported work limitation among beneficiaries by estimating logit models for these sub-samples.

All analyses use the NHIS final annual weight for each individual to account for oversampling, non-coverage, and non-response, and all calculations from estimates, e.g., mean predicted probability, also use the survey weights. We use appropriate methods in Stata (version 10) to account for the complex survey design of the NHIS.

\section{Bivariate Analyses}

Demographic Characteristics. Women make up a substantial majority of both denied and accepted SSI applicants (See Table 2): 61 percent of denied SSI applicants are women, while 63 percent of SSI and 57 percent of dual beneficiaries are women. Women make up only 44 percent of SSDI-only beneficiaries. This may be attributable to lower labor force participation historically; in the 1994-1996 linked NHIS sample women comprised only 37 percent of SSDI beneficiaries. Hispanics are disproportionately represented among both SSI denied applicants and SSI beneficiaries, while comprising less than 7 percent SSDI beneficiaries (9.5 percent of the adult sample is Hispanic). While non-Hispanic blacks comprise just under 11 percent of the total sample, they are disproportionately represented among all categories of respondents with a disability application history, particularly categories including an SSI application: they comprise over one-fourth of rejected SSI applicants, rejected dual applicants, and SSI beneficiaries. They are also disproportionately represented among SSDI denied applicants and beneficiaries, but to a lesser degree than in SSI-related categories.

Education levels are inextricably linked with motivation to work, income, health status, employability, working conditions, and the disability determination process itself, so it is not surprising that educational attainment has a relationship to disability application history. Adults with less than a high school education are over-represented among all respondents who have some disability application history, while those with 16 or more years of education are underrepresented in all categories. High-school dropouts comprise nearly a quarter of rejected SSDI 
applicants over a quarter of SSDI beneficiaries and over half of SSI beneficiaries. Married individuals are underrepresented in SSI and dual categories, particularly beneficiaries--they comprise 68 percent of adult respondents but less than one-fourth of SSI and dual beneficiaries. Similarly, never-married and divorced or separated respondents are overrepresented in the SSIrelated categories.

\section{Self-Reported Health and Labor Force Participation. The NHIS includes respondent-} reported measures of health status, work limitation, height and weight, conditions that limit activities generally, and the number of days confined to bed in the last two weeks. Although one must always view self-reports of health status and work limitation among disability applicants with a degree of caution, these various measures of health status present two strong and consistent patterns: denied applicants report being in considerably worse health than nonapplicants, and beneficiaries appear to be sicker yet. All comparisons between groups are statistically significant, and with the exception of weight differences between rejectees and beneficiaries ( $\mathrm{p}=.04)$, are highly significant $(\mathrm{p}<.0001)$. Less than one percent of non-applicants report their health status as poor (see Table 3), yet approximately 10 percent of denied applicants and over one-fourth of disability beneficiaries do so. Both denied applicants and beneficiaries also report markedly higher levels of fair health--about one-fourth of denied applicants and over one-third of beneficiaries rate their health as only fair. Conversely, while over one-third of nonapplicants report their health as excellent, only 12-13 percent of denied applicants report this, while less than four percent of beneficiaries do so.

Similarly the great majority of respondents across groups report no days confined to bed in the past two week, but there is a similar pattern in bed days reported by denied applicants and beneficiaries. Less than one percent of the non-applicant population reports more than five days of bed confinement; this compares with five to seven percent of denied applicants and over 14 percent of beneficiaries.

Respondents also report how many health conditions they have that limit them in some way. Over 90 percent of non-applicants report no limiting conditions. Over half of denied disability applicants (51-64 percent) report no limiting health conditions, but only 11-15 percent of beneficiaries do so. At the other extreme, about five percent of denied applicants report four or more limiting conditions, and about fourteen percent of beneficiaries do so. 
While self-reports of work limitation should be viewed with caution, particularly among individuals with a disability application history, this measure parallels other health measures and reveals strong differences among non-applicants, denied applicants, and beneficiaries. Less than two percent of non-applicants report a health limitation that makes them unable to work, but this rate is much higher among denied applicants (19-27 percent) and far higher still among beneficiaries (73-76 percent). Conversely 96 percent of non-applicants report no work limitation. Over half of denied applicants (57 to 68 percent) report no work limitation, while that figure is much lower but non-trivial among beneficiaries: nearly 18 percent of SSI recipients report no health limit on their ability to work. The percentages of rejectees and beneficiaries reporting no work limitation are higher for the 1998-2004 data than for the 1994-1996 data, although it is difficult to disentangle secular trends from data artifacts such as reduced linkage rates.

Diagnosis at Time of Disability Determination. Autor and Duggan focus on applicants with musculoskeletal and mental health diagnoses as potentially questionable sources of disability program growth relative to diagnoses that lend themselves to more specific diagnosis and determination of work capacity. Table 4 shows the proportions of denied applicants and disability beneficiaries with diagnoses (by major body systems). Musculoskeletal and mental health diagnoses each account for about a quarter of total applicants. Applicants with a primary mental health diagnosis account for 19 percent of denied applicants and 26 percent of beneficiaries. Applicants with a musculoskeletal impairment account for 27 percent of denied applicants and 22 percent of beneficiaries. Individuals with "ill-defined" conditions account for only six percent of the total but 11 percent of denied applicants. Similarly, individuals whose primary impairment is due to an injury are about eight percent of the total but 12 percent of denied applicants.

Looking across both denied applicants and beneficiaries, applicants with some diagnoses are more likely to report working, report having no work limitation, or report excellent or very good health at time of NHIS interview (see Table 5). Reports of labor force participation range from 16 percent for those with a circulatory system-related diagnosis to 41 percent for those whose primary diagnosis was an injury at time of application. Approximately one-fourth of those with an endocrine or circulatory-related diagnosis report having no work limit at time of NHIS 
interview, while half of those with an "ill-defined" diagnosis do so. About one-third each of those with mental health or musculoskeletal diagnoses report no health limitation on their ability to work. Only eight percent of those with an endocrine-related diagnosis report excellent health at time of interview, while over one-fourth of those with mental retardation, ill-defined conditions, or an injury do so.

\section{Multivariate Analyses}

Two logit models examine the role of beneficiary characteristics among disability recipients on the probability of reporting excellent/very good health and reporting no work limit at time of NHIS interview.

Women are significantly less likely to report excellent/very good health (relative risk of .81), but race has no significant effect. All levels of education are more likely to report good health relative to high-school dropouts. A measure of time from disability determination to NHIS interview is highly significant--greater time since disability determination increases the probability of reporting good health. An increase in one standard deviation of time since determination relative to one standard deviation below the mean increases the probability of reporting good health by 47 percent. Having a mental health diagnosis as a primary condition at time of determination significantly increases the probability of reporting good health relative to diagnoses other than musculoskeletal (relative risk of 1.17), while a musculoskeletal diagnosis decreases the likelihood of good health but not significantly (relative risk of .84, $\mathrm{p}=.07$ ).

While being female decreased the probability of good health, it has no significant effect on the probability of reporting no work limitation at time of interview among beneficiaries. Older beneficiaries are significantly less likely to report no work limit. Although race was not significant in the model of self-reported health, both Hispanics and non-Hispanic blacks are significantly more likely to report no work limitation at time of interview. The effect of education on work limits is less clear than in the model of health: some college significantly decreases the probability relative to high school drop-outs, but having the equivalent of a bachelor's degree or more increases the probability of reporting no work limit, although the levels of significance are marginal ( $\mathrm{p}=.06, .04$ respectively). A mental health diagnosis is not significant, while a musculoskeletal diagnosis significantly decreases the probability of reporting no work limitation $(\mathrm{p}=.01)$. 
Another way of exploring the issue of what applicant characteristics predict possible work capability at time of interview is to examine predictors of labor force participation among denied applicants. Approximately half of respondents rejected prior to interview report working in the past two weeks in the NHIS interview. What predicts which rejectees work? As described above, we use a logit model to estimate the probability that a rejected SSA applicant works at the time of interview. We use a set of demographic and health characteristics as covariates. We also divide our rejected sample into quartiles of time since rejection, and then enter the quartile dummies into our model.

Looking at the results overall, many covariates are statistically significant, but modest in magnitude. As might be expected, respondent-assessed global health and education seem to dominate, particularly education, reflecting work disability as a function both of health and its interaction with job requirements and occupational mobility. The results suggest a monotonic relationship between level of education and probability of employment after rejection (see Table 7), and each level of education is significantly different from the next except for the two highest levels, which are not significantly different from each other. Having just 12 years of education increases the probability of employment after rejection by 30 percent, relative to having less than 12 years of school. On the other hand, modest differences in health relative to excellent health (very good or good health) do not significantly decrease the probability of employment—it takes fair or poor health to decrease the probability significantly, with those in fair/poor health having 61 percent of the probability of employment compared to rejectees in excellent health. As noted previously, respondent-assessed health measures should be interpreted cautiously in labor force models.

Women are less likely to work following rejection than men, as are non-Hispanic blacks relative to non-Hispanic whites. Younger age groups are all more likely to work than the oldest reference group (ages 55-64). This may reflect some combination of unobserved health status, alternatives available (e.g., nondisability pensions, private savings) and the time horizon remaining before normal retirement age. However, the relationship is not monotonic - "midcareer" rejectees ages 35-44 are more likely to return to work than either the younger or older cohorts, and these differences with neighboring cohorts are significant. This middle cohort's greater propensity to work following rejection may be greater than younger and older cohorts' for different reasons: the younger cohort may lack job experience and a history of attachment to 
the labor force, while for older cohorts the majority of their potential working years are behind them, they may be less attractive to employers due to age, and alternatives to work such as pensions might be more available.

As noted above, poor health decreased the probability of employment, but other health measures yielded more muddled results. Having any health conditions relative to none lowers the probability of employment; there are no significant differences between different condition counts above zero. Condition counts may be too crude a health measure, since they make no distinction between major and minor limiting conditions. Bed days also appear to be an imprecise measure of work disability. We included measures of overweight and obesity as alternate measures of disability. Interestingly, they are significant, but in the "wrong" direction if regarded as measures of ill health: obese individuals were somewhat more likely to work following rejection, although not significantly so, while overweight individuals were 15 percent more likely to return to work, and this result was significant (CI of 1.04-1.24). Our sample includes a very small number of underweight (BMI less than 18.5) individuals, but analysis including only normal-weight and overweight individuals yields substantially similar results, suggesting that our findings are not driven by underweight individuals.

SSI rejectees are less likely to work following rejection than SSDI rejectees. Although not significant, this result makes intuitive sense, as individuals who apply and are rejected exclusively by the SSI program are likely to have a more tenuous connection to the labor forceif they had sufficient work history to apply for SSDI, they probably would have done so. But individuals rejected by both programs are 29 percent more likely to work subsequently than SSDI rejectees (CI 1.16-1.42). It may be that dual rejection most definitely forecloses the possibility of SSA disability benefits in the near future, leaving no incentive to remain out of the labor force in hopes of eventual success.

Time since rejection increases the probability that a rejectee is working at time of interview, relative to the reference group, the most recent quartile of rejectees. All quartiles since rejection increase the probability of work relative to the first quartile. Although the point estimates suggest an increasing relationship, the estimates for the second through fourth quartiles are not significantly different from each other, with increases in the probability of work from 20 to 45 percent relative to the most recent quartile. 
Observing mortality during follow-up also provides an objective measure of health differences between rejectees, applicants, and non-applicants. The NHIS linkage with the NDI allows us to evaluate mortality during the NDI follow-up period from time of interview to 2002. Table 8 shows unadjusted mortality rates by applicant status for our entire sample and by age group. These repeat the pattern observed at time of interview: rejectees are more likely to die than the non-applicant population, but beneficiaries are likelier still to die during follow-up (all bivariate comparisons are highly significant at $\mathrm{p}<.001$ ). Given that our bivariate analyses do not control completely for age, we also estimate a Cox proportional hazards model of mortality that includes as covariates applicant status at time of interview and age at interview. Table 8 reports relative risks of death during follow-up with the non-applicant group as the reference group. Denied applicants are more than twice as likely to die during follow-up as non-applicants after adjusting for age, ranging from a hazard ratio of 2.7 for SSDI rejectees to 2.84 for SSI rejectees. But beneficiaries are even more likely to die, with hazards ranging from 6.24 for SSDI or SSI beneficiaries to 6.97 for dual beneficiaries.

\section{Discussion}

Health Differences. Respondent-assessed health measures in the NHIS paint a consistent picture of differences between rejectees and applicants on the one hand, and rejectees and nonapplicants on the other: rejectees describe themselves as healthier and less limited than do successful applicants, but sicker than non-applicants.

Given the concerns about self-reported health in models of labor-force participation, respondent-assessed work-limitation might be viewed as particularly suspect, since questions about work limitation go directly to the relationship between health and work. However, the pattern of responses to the work limitation questions is consistent with other measures of health, with beneficiaries much more likely to report work limitation than rejected applicants. We also observe a sizeable number of beneficiaries who do not report total inability to work (only about three-quarters do so) and a non-trivial number-14-18 percent - who report no work limitation at all. These reports on the part of beneficiaries lends credence to Benitez-Silva and colleagues' argument that survey respondents are generally honest in their self-assessment of health (2006), and that disability applicants and rejectees do not systematically overstate their limitations. In 
general we find a consistent pattern of responses, whether the health question is narrow and specific (e.g., bed days in past two weeks) or more global.

Differences between applicant groups on the objective health measure of mortality suggest that the differences observed in respondent-assessed health are not merely the result of systematic exaggeration of health problems among rejectees. Rejected applicants are more than twice as likely to die and beneficiaries about six times as likely to die during follow-up as nonapplicants. Mortality has its own limitations: it does not correlate perfectly with work disability, as a condition can be quite limiting, yet not fatal, and the converse is also true. But at a minimum mortality is a rough check on the reliability of respondent-assessed measures, and suggest that real differences in health status underlie self-reports.

Labor Force Participation Among Rejectees. We find that over half of rejected applicants are working at time of NHIS interview. This figure is higher than that found by several similar studies (e.g., Bound, 1989 and Chen and van der Klauuw, 2007), but lower than that found by a recent study using longitudinal SSA administrative data (von Wachter, Song, and Manchester, 2007). We believe these differences may be due to several factors.

Our sample includes rejected applicants from both SSA disability programs, and we distinguish between SSDI-only, SSI-only, and dual rejectees. Perhaps more importantly, we adopt a strict definition of rejectee, and classify as beneficiaries those applicants with a record of successful application in one program and rejection from the other.

Estimates of work rates also vary with the definition of what defines work. We use a report of being employed in the past two weeks. Bound (1989) finds that 33 percent of rejected workers reported working in the past month, which most closely matches our definition, but about 50 percent report working at some point in the past 12 months. Von Wachter, Song, and Manchester (2007) use any reported earnings in the past 12 months as a measure of work and find work rates among rejectees of 58-67 percent.

Our linked data contains information from the MBR file on applications since 1962. This ability to identify respondents rejected for benefits years before NHIS interview might also affect the work rates observed, as most previous work looked at employment within three years or less of rejection (Bound, 1989 and Chen and van der Klaauw, 2007). The NHIS interview takes place a mean of five years following disability determination, and our logit models of work, 
health, and work limitation suggest that time since rejection increases the probability of working at time of interview for denied applicants and better health and no self-reported work limitation among beneficiaries. Our finding of fairly high work rates among denied applicants mirrors that of one other study with a long follow-up period after rejection using longitudinal SSA administrative data, which finds high work levels in the decade following denial (von Wachter, Song, and Manchester, 2007).

The results of the multivariate analysis of work among rejectees generally mirror the disability determination process itself: just as poorly educated, sicker applicants are more likely to be awarded benefits, poor health and low levels of education are negatively correlated with work among rejectees. Mid-career rejectees are more likely to work following rejection than either younger or older cohorts, and as noted, higher levels of education are highly predictive of work.

Finally, our results suggest that time since rejection increases the probability of a rejectee returning to the labor force. This delayed return to work may reflect a mix of factors: individuals may remain out of the labor force until their disability claims are completely adjudicated, and a substantial number of rejectees may also experience some recovery from the conditions that prompted the disability application. However, these results must be interpreted with caution as we cannot distinguish the effects of time since rejection from cohort effects, such as the economic conditions and stringency of SSA review that may have been in effect at time of rejection.

We find that individuals rejected for both SSI and SSDI benefits are more likely to work following rejection than those rejected from one program. Individuals who apply for both programs are likely to have enough work history to potentially be eligible for SSDI benefits, yet their earnings and assets are sufficiently low for them to potentially meet the stringent income requirements of SSI. One possible explanation for our finding is that dual technical eligibility (i.e., sufficient quarters of coverage but still very low income) is a marker for an economically marginal worker. Such low-wage workers may be more likely to be induced to apply by economic conditions, but have a relatively weak case on the merits of health. Thus once rejected, they may be more likely to be healthy enough to return to work than other rejectees. Such an interpretation would be consistent with the findings of von Wachter, Song, and 
Manchester (2007), who identify a class of workers with permanently low earnings who appear motivated to apply due to adverse economic conditions, but who are largely denied benefits.

\section{Limitations}

NHIS respondents may not be representative of all SSDI/SSI recipients and rejected applicants if SSDI/SSI recipients and rejectees are disproportionately found in populations not sampled by the NHIS, e.g., institutionalized individuals. In addition, not all NHIS respondents are eligible for linkage and successfully linked. There is observable bias in the linkage rates, and analyses suggest that there are significant differences in age, race, insurance status, and income between matched and unmatched respondents (CDC/NCHS 2006). This study uses the matched data to examine the health and labor force participation of disability applicants, but the experience of matched respondents may differ from that of unmatched respondents, and thus may not be generalized to the population of interest.

In addition, our analyses use NHIS data from 1998-2004, and our mean period of time since determination is approximately five years prior to interview. The experience of these respondents may not be generalizable to more recent cohorts of applicants.

Because we do not have an earnings history for all matched respondents, or other indication from the SSA whether a given participant is eligible for SSDI benefits, we are not able to discern which respondents in our sample are insured for SSDI. Thus the "non-applicants" in our comparisons of groups contains an unknown mix of two kinds of people: those who are insured for SSDI but never applied for benefits, and those who are not insured for SSDI. An analysis of non-elderly (mean age 55) Health and Retirement Study respondents suggests that 61 percent of female and 83 percent of male respondents were insured for SSDI, and also finds that those not insured for SSDI are more likely to report a work-limiting disability (Mitchell and Phillips 2001). If some substantial portion of the non-applicant population are in poor health and do not apply for benefits because they know they are not eligible, this would tend to diminish observed differences in health status between non-applicants and applicants (rejectees and beneficiaries). For example, if we could limit our non-applicant group to those non-applicants insured for SSDI or income-eligible for SSI, we might expect to see larger mortality differences than those observed between non-applicants and applicants. 


\begin{tabular}{|l|c|c|}
\hline \multicolumn{3}{|l|}{ Table 1: Counts and Percentages of NHIS Respondents by SSA } \\
Disability Applicant Status at Time of Interview
\end{tabular}

$\mathrm{n}=163,395$ SSA-linked adult respondents from 1998-2004 NHIS 


\begin{tabular}{|c|c|c|c|c|c|c|c|c|}
\hline \multirow{2}{*}{ Characteristic } & \multicolumn{3}{|c|}{ Rejected } & \multicolumn{3}{|c|}{ Beneficiary } & \multirow{2}{*}{$\begin{array}{c}\text { Non- } \\
\text { applicant }\end{array}$} & \multirow[t]{2}{*}{ All } \\
\hline & SSDI & SSI & Both & SSDI & SSI & Both & & \\
\hline \multicolumn{9}{|l|}{ Sex } \\
\hline Female & 52.05 & 60.9 & 47.8 & 43.9 & 63.4 & 57.2 & 50.1 & 50.2 \\
\hline Male & 48.0 & 39.1 & 52.2 & 56.1 & 36.7 & 42.8 & 50 & 49.8 \\
\hline \multicolumn{9}{|l|}{ Race/Ethnicity } \\
\hline Hispanic & 9.8 & 15.3 & 9.3 & 6.8 & 13.5 & 10.5 & 9.5 & 9.5 \\
\hline Non-Hispanic White & 70.7 & 52.7 & 61.3 & 75.6 & 55.4 & 65.4 & 76.8 & 75.7 \\
\hline Non-Hispanic Black & 16.8 & 28.1 & 26.2 & 15.6 & 27.0 & 21.2 & 9.6 & 10.8 \\
\hline Other Race & 2.7 & 3.9 & 3.2 & 2.0 & 4.1 & 2.2 & 4.2 & 4.1 \\
\hline \multicolumn{9}{|l|}{ Education } \\
\hline Less than 12 years & 24.3 & 39.6 & 28.6 & 25.8 & 53.4 & 37.9 & 10.8 & 13.0 \\
\hline 12 years & 36.8 & 33.3 & 37.2 & 37.3 & 29.4 & 35.3 & 28.8 & 29.4 \\
\hline 13-15 years & 29.1 & 21.1 & 28.1 & 27.1 & 14.3 & 21.9 & 30.0 & 29.4 \\
\hline 16 years & 7.0 & 4.8 & 4.7 & 7.3 & 2.3 & 4.0 & 19.7 & 18.3 \\
\hline 17 years or more & 2.9 & 1.2 & 1.4 & 2.5 & 1.0 & 1.0 & 10.1 & 9.8 \\
\hline \multicolumn{9}{|l|}{ Age Group } \\
\hline 25-34 Years & 11.8 & 26.3 & 24.2 & 7.7 & 16.7 & 19.6 & 29.2 & 27.9 \\
\hline 35-44 Years & 26.0 & 28.4 & 32.4 & 19.7 & 26.3 & 29.4 & 33.0 & 32.3 \\
\hline 45-54 Years & 30.8 & 23.6 & 23.9 & 28.2 & 27.2 & 25.5 & 23.3 & 23.6 \\
\hline 55-64 Years & 31.5 & 21.7 & 19.5 & 44.4 & 29.9 & 25.5 & 14.6 & 16.2 \\
\hline \multicolumn{9}{|l|}{ Marital Status } \\
\hline Married & 58.7 & 46.8 & 44.7 & 56.1 & 23.1 & 23.0 & 70.6 & 68.1 \\
\hline Widowed & 3.8 & 5.0 & 2.9 & 3.7 & 5.8 & 4.3 & 1.3 & 1.6 \\
\hline Divorced/Separated & 16.6 & 21.5 & 23.7 & 21.6 & 30.9 & 37.1 & 11.24 & 12.5 \\
\hline Never Married & 13.7 & 19.3 & 18.0 & 13.9 & 30.9 & 27.7 & 11.2 & 11.9 \\
\hline
\end{tabular}




\begin{tabular}{|c|c|c|c|c|c|c|c|c|}
\hline \multirow{2}{*}{ Characteristic } & \multicolumn{3}{|c|}{ Rejected } & \multicolumn{3}{|c|}{ Beneficiary } & \multirow{2}{*}{$\begin{array}{c}\text { Non- } \\
\text { applicant }\end{array}$} & \multirow[t]{2}{*}{ All } \\
\hline & SSDI & SSI & Both & SSDI & SSI & Both & & \\
\hline Living with Partner & 7.2 & 7.3 & 10.7 & 4.7 & 9.2 & 7.9 & 5.6 & 5.8 \\
\hline \multicolumn{9}{|l|}{ Region in U.S. } \\
\hline East & 17.8 & 19.1 & 13.4 & 19.8 & 19.5 & 18.9 & 18.9 & 18.8 \\
\hline Midwest & 24.0 & 22.6 & 25.2 & 21.9 & 20.6 & 19.2 & 26.3 & 25.9 \\
\hline South & 38.8 & 42.1 & 46.6 & 43.8 & 42.1 & 44.2 & 36.7 & 37.4 \\
\hline West & 19.5 & 16.2 & 14.8 & 14.4 & 17.8 & 17.8 & 18.1 & 17.9 \\
\hline
\end{tabular}




\begin{tabular}{|c|c|c|c|c|c|c|c|c|}
\hline \multirow{2}{*}{ Characteristic } & \multicolumn{3}{|c|}{ Rejected } & \multicolumn{3}{|c|}{ Beneficiary } & \multirow[t]{2}{*}{ Non-applicant } & \multirow[t]{2}{*}{ All } \\
\hline & SSDI & SSI & Both & SSDI & SSI & Both & & \\
\hline \multicolumn{9}{|c|}{ Respondent-Assessed Health Status } \\
\hline Poor & 9.7 & 9.8 & 10.4 & 27.8 & 28.9 & 28.4 & 0.6 & 2.6 \\
\hline Fair & 24.9 & 25.3 & 24.7 & 36.2 & 35.3 & 38.0 & 5.1 & 7.7 \\
\hline Good & 34.5 & 31.5 & 33.2 & 25.4 & 23.4 & 22.8 & 23.2 & 23.7 \\
\hline Very Good & 18.7 & 19.7 & 19.6 & 7.2 & 8.5 & 7.0 & 35.5 & 33.2 \\
\hline Excellent & 12.2 & 13.7 & 11.9 & 3.4 & 3.8 & 3.8 & 35.6 & 32.8 \\
\hline \multicolumn{9}{|l|}{ Work Limitation } \\
\hline Unable to Work & 26.9 & 19.5 & 21.9 & 75.2 & 72.7 & 75.5 & 1.5 & 6.6 \\
\hline Limited in Kind/Amount & 16.3 & 12.67 & 13.9 & 10.5 & 9.5 & 9.4 & 2.8 & 3.7 \\
\hline No Limit & 56.8 & 67.8 & 64.2 & 14.3 & 17.8 & 15.2 & 9.6 & 9.0 \\
\hline \multicolumn{9}{|l|}{ Body Mass Index (BMI) } \\
\hline $\mathrm{BMI}<18$ & 3.5 & 4.5 & 2.5 & 3.6 & 5.3 & 5.7 & 2.4 & 2.6 \\
\hline $\mathrm{BMI}<25$ & 42.2 & 47.9 & 48.6 & 40.2 & 40.6 & 41.0 & 59.0 & 57.1 \\
\hline $25<=\mathrm{BMI}<30$ & 45.6 & 39.5 & 40.3 & 41.9 & 37.2 & 35.5 & 33.7 & 34.5 \\
\hline BMI $>=30$ & 9.2 & 8.2 & 8.8 & 14.3 & 16.9 & 17.8 & 5.0 & 5.9 \\
\hline \multicolumn{9}{|l|}{ Limiting Conditions } \\
\hline No conditions & 51.3 & 63.6 & 59.6 & 11.0 & 14.6 & 12.8 & 93.9 & 87.6 \\
\hline One condition & 29.5 & 19.3 & 23.2 & 44.3 & 40.8 & 43.29 & 4.7 & 7.7 \\
\hline Two conditions & 10.3 & 8.3 & 9.0 & 19.5 & 19.4 & 16.9 & 0.9 & 2.3 \\
\hline Three conditions & 4.4 & 4.0 & 3.5 & 11.0 & 11.3 & 12.4 & 0.3 & 0.1 \\
\hline Four or more & 4.5 & 4.9 & 4.8 & 14.2 & 13.8 & 14.6 & 0.2 & 1.2 \\
\hline \multicolumn{9}{|l|}{ Bed days last 2 weeks } \\
\hline No bed days & 83.4 & 85.0 & 85.5 & 74.1 & 73.0 & 73.2 & 95.5 & 93.9 \\
\hline 1-4 bed days & 9.5 & 9.9 & 9.5 & 12.9 & 13.6 & 14.5 & 3.8 & 4.5 \\
\hline More than 5 days & 7.1 & 5.1 & 5.0 & 13.0 & 13.4 & 12.4 & 0.76 & 1.6 \\
\hline
\end{tabular}




\begin{tabular}{|c|c|c|c|c|c|c|c|c|}
\hline \multirow{2}{*}{ Characteristic } & \multicolumn{3}{|c|}{ Rejected } & \multicolumn{3}{|c|}{ Beneficiary } & \multirow[t]{2}{*}{ Non-applicant } & \multirow[t]{2}{*}{ All } \\
\hline & SSDI & SSI & Both & SSDI & SSI & Both & & \\
\hline \multicolumn{9}{|c|}{ Labor Force Participation } \\
\hline Employed & 49.6 & 54.4 & 58.9 & 10.3 & 6.1 & 8.8 & 84.2 & 78.7 \\
\hline Unemployed & 6.8 & 5.9 & 7.6 & 1.5 & 2.0 & 2.7 & 2.5 & 2.7 \\
\hline Not in Labor Force & 43.6 & 39.7 & 33.5 & 88.2 & 92.0 & 88.5 & 13.2 & 18.7 \\
\hline
\end{tabular}




\begin{tabular}{|c|c|c|c|}
\hline Major Diagnostic Category & Rejected & Beneficiary & Total \\
\hline Infectious & $1.2 \%$ & $1.7 \%$ & $1.5 \%$ \\
\hline Neoplasm & $1.8 \%$ & $2.8 \%$ & $2.4 \%$ \\
\hline Endocrine/Nutritional & $4.8 \%$ & $6.3 \%$ & $5.7 \%$ \\
\hline Mental Health & $19.1 \%$ & $26.0 \%$ & $23.5 \%$ \\
\hline Mental Retardation & $3.4 \%$ & $6.3 \%$ & $5.2 \%$ \\
\hline Nervous System/Sensory & $7.4 \%$ & $8.5 \%$ & $8.1 \%$ \\
\hline Circulatory & $5.6 \%$ & $9.8 \%$ & $8.3 \%$ \\
\hline Respiratory & $3.3 \%$ & $3.4 \%$ & $3.3 \%$ \\
\hline Digestive & $2.3 \%$ & $1.7 \%$ & $1.9 \%$ \\
\hline Musculoskeletal & $26.6 \%$ & $21.7 \%$ & $23.5 \%$ \\
\hline Ill Defined & $10.8 \%$ & $3.7 \%$ & $6.3 \%$ \\
\hline Injury & $12.1 \%$ & $5.4 \%$ & $7.9 \%$ \\
\hline
\end{tabular}

Note: excludes some diagnostic categories with very low frequencies.

\begin{tabular}{|c|c|c|c|c|c|c|}
\hline & \multicolumn{3}{|c|}{ Rejected } & \multicolumn{3}{|c|}{ Beneficiaries } \\
\hline & SSDI & SSI & Dual & SSDI & SSI & Dual \\
\hline Mental Health & 0.07 & 0.15 & 0.15 & 0.18 & 0.26 & 0.25 \\
\hline Musculoskeletal & 0.15 & 0.15 & 0.2 & 0.21 & 0.1 & 0.16 \\
\hline
\end{tabular}


Table 6: Self-Reported Health and Work Status at Time of NHIS Interview, by Primary Diagnosis at Time of Disability Determination

\begin{tabular}{|c|c|c|c|c|c|c|c|c|c|c|c|c|}
\hline & Infection & Neoplasm & Endocrine & $\begin{array}{l}\text { Mental } \\
\text { Health }\end{array}$ & $\begin{array}{c}\text { Mental } \\
\text { Retardation }\end{array}$ & $\begin{array}{c}\text { Nervous/ } \\
\text { Sensory }\end{array}$ & Circulatory & Respiratory & Digestive & $\begin{array}{c}\text { Musculo- } \\
\text { skeletal }\end{array}$ & $\begin{array}{c}\text { Ill } \\
\text { Defined }\end{array}$ & Injury \\
\hline Working & $25.4 \%$ & $26.5 \%$ & $17.7 \%$ & $23.1 \%$ & $26.8 \%$ & $26.5 \%$ & $16.0 \%$ & $20.2 \%$ & $27.9 \%$ & $28.6 \%$ & $39.8 \%$ & $41.2 \%$ \\
\hline $\begin{array}{l}\text { No Work } \\
\text { Limit }\end{array}$ & $44.0 \%$ & $33.7 \%$ & $26.6 \%$ & $33.9 \%$ & $41.9 \%$ & $30.5 \%$ & $26.3 \%$ & $29.5 \%$ & $33.8 \%$ & $33.5 \%$ & $50.5 \%$ & $45.8 \%$ \\
\hline $\begin{array}{l}\text { Exc/V } \\
\text { Good } \\
\text { Health }\end{array}$ & $19.0 \%$ & $12.5 \%$ & $8.1 \%$ & $20.5 \%$ & $25.4 \%$ & $23.4 \%$ & $9.4 \%$ & $8.6 \%$ & $11.9 \%$ & $16.6 \%$ & $26.4 \%$ & $27.1 \%$ \\
\hline
\end{tabular}

Note: Some Diagnostic/Body System categories omitted due to small sample size 


\begin{tabular}{|l|c|}
\hline \multicolumn{2}{|c|}{ Table 7: Relative Risk of Employment Among Denied Applicants } \\
\hline Female & Relative Risk of Employed \\
\hline Non-Hispanic White (reference) & 0.77 \\
\hline Hispanic & 0.98 \\
\hline Non-Hispanic Black & 0.84 \\
\hline Other Race & 0.87 \\
\hline Education <12 years (reference) & \\
\hline Education 12 years & 1.26 \\
\hline Education 13-15 years & 1.41 \\
\hline Education 16 years & 1.53 \\
\hline Education >16 years & 1.62 \\
\hline Age 25-34 & 1.27 \\
\hline Age 35-44 & 1.47 \\
\hline Age 45-54 & 1.29 \\
\hline Age 55-64 (reference) & \\
\hline Married (reference) & 1.00 \\
\hline Widowed & 1.22 \\
\hline Divorced/separated & 0.90 \\
\hline Never married & 0.67 \\
\hline Marital status unknown & 1.05 \\
\hline Region Northeast (reference) & 0.86 \\
\hline Region Midwest & 0.63 \\
\hline Region South & \\
\hline Region West & \\
\hline Health Excellent (reference) & \\
\hline Health Very Good & \\
\hline Health Good & \\
\hline Health Fair/Poor & \\
\hline
\end{tabular}


Table 7: Relative Risk of Employment Among Denied Applicants (cont'd)

\begin{tabular}{|l|l|}
\hline \multicolumn{1}{|c|}{ Covariate } & Relative Risk of Employed \\
\hline BMI<25 (reference) & 1.15 \\
\hline BMI 25-30 & 1.11 \\
\hline BMI>30 & \\
\hline No limiting conditions (reference) & 0.81 \\
\hline One limiting health condition & 0.74 \\
\hline Two limiting health conditions & 0.58 \\
\hline Three or more health conditions & \\
\hline No bed days past 14 days (reference) & 0.98 \\
\hline Bed days 1-4 & 0.81 \\
\hline Bed days 5 or more & 1.45 \\
\hline Rejected SSDI only (reference) & 1.31 \\
\hline Rejected SSI only & 0.96 \\
\hline Rejected SSDI and SSI & 1.29 \\
\hline $\begin{array}{l}\text { Time since rejected—-most recent quartile } \\
\text { (ref) }\end{array}$ & \\
\hline Time since rejected-second quartile & \\
\hline Time since rejected-third quartile & \\
\hline Time since rejected-fourth quartile & \\
\hline
\end{tabular}




\begin{tabular}{|l|c|}
\hline \multicolumn{2}{|l|}{ Table 8: Hazard of Mortality During Follow-Up Period by Applicant Status } \\
\hline \multicolumn{1}{|c|}{ Applicant Status } & Hazard Ratio of Mortality (Confidence Interval) \\
\hline Rejected SSDI & $2.68(2.16-3.32)$ \\
\hline Rejected SSI & $2.84(2.31-3.49)$ \\
\hline Dual Rejectee & $3.67(3.12-4.33)$ \\
\hline SSDI Beneficiary & $6.24(5.67-6.88)$ \\
\hline SSI Beneficiary & $6.24(5.56-7.00)$ \\
\hline Dual Beneficiary & $6.97(5.94-8.18)$ \\
\hline Non-applicant & 1 (reference group) \\
\hline
\end{tabular}

$\mathrm{n}=162,861$

Results from Cox proportional hazards model that also controls for age and age squared. Applicant status is at time of interview; mortality during the follow-up period from time of interview-2006. 


\section{RECENT WORKING PAPERS FROM THE CENTER FOR RETIREMENT RESEARCH AT BOSTON COLLEGE}

What Explains State Variation in SSDI Application Rates?

Norma B. Coe, Kelly Haverstick, Alicia H. Munnell, Anthony Webb, December 2011

How Do Subjective Mortality Beliefs Affect the Value of Social Security and the Optimal Claiming Age?

Wei Sun and Anthony Webb, November 2011

How Does the Personal Income Tax Affect the Progressivity of OASI Benefits?

Norma B. Coe, Zhenya Karamcheva, Richard Kopcke, Alicia H. Munnell, November 2011

The Pension Protection Act of 2006 and Diversification of Employer Stock in Defined Contribution Plans

Gary V. Engelhardt, November 2011

Prescription Drug Insurance Coverage, Drug Utilization, and Cost-Related NonAdherence: Evidence from the Medicare Part D Expansion

Gary V. Engelhardt, November 2011

Social Security on Auto-Pilot: International Experience with Automatic Stabilizer Mechanisms

Barry Bosworth and R. Kent Weaver, November 2011

The Impact of Unemployment Insurance Extensions on Disability Insurance Application and Allowance Rates

Matthew S. Rutledge, October 2011

Do Couples Self-Insure? The Effect of Informal Care on a Couple's Labor Supply

Norma B. Coe, Meghan Skira, and Courtney Harold Van Houtven, October 2011

How Prepared are State and Local Workers for Retirement?

Alicia H. Munnell, Jean-Pierre Aubry, Josh Hurwitz, and Laura Quinby, October 2011

Do Low-Income Workers Benefit from 401(k) Plans?

Eric Toder and Karen E. Smith, September 2011

Corporate Pension Plan Investments in Alternative Assets: Determinants and Consequences

Divya Anantharaman, September 2011

All working papers are available on the Center for Retirement Research website

(http://crr.bc.edu) and can be requested by e-mail (crr@bc.edu) or phone (617-552-1762). 